\title{
Sexually transmitted diseases in children: herpes simplex virus infection, cytomegalovirus infection, hepatitis $B$ virus infection and molluscum contagiosum
}

\author{
A Nageswaran, G R Kinghorn
}

Common sexually transmitted diseases (STD) in adults may occur in children as a result of vertical transmission, non-sexual child to child or adult to child contact, sexual abuse, or voluntary sexual activity. Viral STD are of particular concern as some viruses acquired through vertical transmission may result in fatal neonatal illness, permanent nervous system damage, recurrent disease in childhood and, as in the case of Hepatitis B infection, other long term complications. This review considers childhood illnesses caused by herpes simplex virus (HSV), cytomegalovirus (CMV), hepatitis $B$ virus (HBV), and molluscum contagiosum.

\section{Herpes simplex virus}

An historical overview

Genital herpes infection was first clearly described by John Astruc, a French physician, in $1736 .{ }^{1}$ By the end of the nineteenth century, the venereal transmission of genital herpes, the varying clinical presentations in both males and females, the recurrent nature of the condition and the histology of herpetic vesicle had all been described. Tissue culture of HSV in rabbit testicular fragments was first reported in 1925 and definitive diagnosis became possible from the late $1950 \mathrm{~s}$ in conventional tissue culture systems. ${ }^{2}$ Though a difference between herpes febrilis and venereal herpes was suggested by Lipshutz as early as 1921, it was only in the late 1960s that the existence of the two viral types, HSV1 and HSV2, was demonstrated. Thereafter, viral typing methods were developed which allowed the epidemiology of these infections to be clarified. The recognition of type-specific viral glycoproteins $\mathrm{gGl}$ and gG2 in 1985, has now made serological differentiation possible and has facilitated new sero-epidemiological studies. ${ }^{3-5}$

In the neonatal period, HSV infections can cause high mortality and morbidity. The first written report of neonatal HSV infection appeared in $1935 . .^{6}$ After the neonatal period, genital HSV infection is rarely diagnosed in children. The first case of childhood genital herpes was described in 1853 in an abused 7 year old girl. ${ }^{7}$ Only relatively recently have further reports of transmission through sexual abuse appeared in the English literature.

\section{Epidemiology}

Intra-uterine infection is rare. ${ }^{8}$ It occurs as a consequence of transplacental or ascending infection. Although it is more likely to occur with first episodes of maternal herpes, it has also been reported following recurrent infection and asymptomatic viral shedding. Risk factors associated with intra-uterine transmission require further clarification.

Neonatal HSV infections usually occur as a result of transmission during delivery. The incidence of neonatal $\mathrm{HSV}$ infection varies in different populations. In the UK, a rate of 2-3 per 100,000 births has been reported. ${ }^{9}$ In black populations in the USA the rate is about $13 / 100,000$ births. In Africa, neonatal HSV is reportedly rare; the almost universal exposure to HSV2 prior to pregnancy has been postulated as an explanation for this observation. ${ }^{10}$

Although HSV1 infections are being more commonly diagnosed, around $80 \%$ of neonatal infections are caused by HSV2. The risk of acquiring neonatal infection from a recurrent maternal infection at term, is reported to be less than $8 \%$. The risk is much higher with primary infection at term; as high as $50 \%$ was reported by Nahmias. ${ }^{11}$ However, most infants with neonatal HSV are born to mothers with no history of symptomatic genital herpes at any time, who asymptomatically shed HSV at delivery. ${ }^{12}{ }^{13}$ This may occur in $10 \%$ or more of women who acquire primary herpes during pregnancy and in $1-2 \%$ of those who acquire the infection before pregnancy. Reports from the USA indicate a 10 fold increase in the incidence of neonatal HSV during the 1980 s, following an increase in genital HSV in the general population. ${ }^{14}$ Although the incidence of adult genital herpes shows a similar rising trend in the UK, the incidence of neonatal HSV infection still remains very low. The reasons for this transatlantic difference remain uncertain.

Genital herpes infection in childhood is uncommon. Early case reports in children failed to speculate about its method of acquisition. ${ }^{15}{ }^{16}$ Lazar in $1955^{17}$ described a 4 year old girl with primary herpetic vulvovaginitis whose mother had recurrent herpetic lesion on her fingers and suggested that the transmission was through nonvenereal contact with a virus shedding adult. Nahmias et al in $1968^{7}$ reported six cases, in five girls aged between 7-12 years and a boy aged 3 years, and observed that such infections in children can be transmitted either venereally or nonvenereally. He demonstrated HSV1 from both the genital lesions and mouth of two of his cases. Although earlier reports suggested that HSV1 genital lesions could be assumed to be transmitted non-sexually, later case 
reports of HSV1 genital herpes in children with proven sexual transmission clearly demonstrated that detailed enquiry regarding sexual exposure is an essential part of the management of genital HSV infection, irrespective of the HSV type. ${ }^{18-21}$

The risk of acquiring STD by the victims of sexual abuse is related to prevalence of STDs among the adults in different populations. Lindsay in $1992^{22}$ reviewed the literature on reported STD among abused children and noted that the risk of acquiring a sexually transmitted disease (excluding ureaplasma, mycoplasma and bacterial vaginosis) varied between $<1 \%$ and $20 \%$. In all studies, HSV was rarely found. Gardner ${ }^{23}$ could find only 1 case of HSV among 209 abused girls. Asymptomatic infection, said to be as high as $50 \%$ among adults, ${ }^{24}$ may also occur in children. However, surveys based on typespecific serological assays in the USA has shown a low HSV2 seroprevalence rate of less than $0.3 \%$ in children below 15 years of age. ${ }^{4}$ Ano-rectal HSV infection in sexually abused boys has, so far, not been reported despite this being a common cause of non-gonococcal proctitis in sexually active homosexual males and male children being at higher risk of sexual abuse at a younger age than girls. ${ }^{25} 26$

\section{Clinical features}

The rare congenital HSV infection presents with widespread cutaneous HSV lesions and scaring at birth, usually with accompanying signs of damage to the central nervous system. ${ }^{8}$

Neonatal HSV infection can present with localised disease limited to skin, eyes and mouth (SEM) or life threatening disseminated disease involving multiple organs. Central nervous system involvement can be a part of the disseminated $\mathrm{HSV}$ infection, resulting from viraemia, or can occur in isolation relatively later in neonatal life when it is thought to be due to retrograde axonal transmission. ${ }^{27}$

The presence of discrete vesicles is the hallmark of SEM. Lesions usually appear during the first week of life. Eye involvement, which can be the sole site of infection and be caused by both HSV1 and HSV2, can manifest with keratoconjunctivitis or, later, with chorio-retinitis. Gingivostomatitis is a rare presentation. ${ }^{8}$

Disseminated HSV disease can also be caused by both viral types and usually becomes evident about 7-10 days after birth. The neonate shows clinical features similar to those of bacterial sepsis with multi-organ involvement. When cutaneous vesicles are absent (in about $20 \%$ cases), clinical diagnosis can be very difficult. It is often fulminant, producing severe hepatitis, thrombocytopenia, intra-vascular coagulation and hypotension with or without meningo-encephalitis and pneumonia. Mortality in the absence of therapy exceeds $80 \%$, the commonest cause of death being HSV pneumonitis and disseminated intra-vascular coagulopathy.

HSV encephalitis occurs later in neonatal life and is usually caused by HSV2. Initial symptoms of fever, lethargy and poor feeding are followed within 24-48 hours by focal seizures which soon become generalised. The CSF can be normal or show elevated protein and lymphocytosis. Cutaneous evidence of HSV is frequently absent in this form of neonatal HSV. The mortality in untreated neonates is about $50 \%$ and is usually related to brain stem involvement. With rare exceptions, survivors are left with neurological impairment.

The maternal HSV immune status affects the rate and outcome of infection and the clinical manifestations in neonates exposed to HSV at delivery. ${ }^{28}$ Sullender ${ }^{29}$ found significantly low levels of the gG2 antibody in 17 neonates with neonatal HSV2 infection compared to those who were exposed but remained uninfected. Ashley ${ }^{30}$ found no antibodies to gG2 in all four neonates who developed neonatal HSV in his study, compared to $83 \%$ of exposed neonates who remained uninfected. Further evidence for the importance of type-specific antibody status of the neonate comes from the finding by Brown et $a l^{31}$ that mothers who acquire HSV2 close to term and who are sero positive for HSV1, have a risk of transmitting to their neonates equal to that of seronegative mothers with primary HSV2 infection at term. The majority of infants with disseminated infection have no neutralising antibodies to the infecting or heterologous strain and have low levels of antibody-dependent cellular cytotoxicity. ${ }^{32} 33$ In contrast, most infants with localised encephalitis have some detectable antibodies at the onset of disease, whilst those with SEM infection are in an intermediate category.

Other host factors are also important as the prognosis for neonatal HSV is poorer in premature infants than in full-term neonates. ${ }^{34}$

Beyond the neonatal period, childhood genital herpes resembles the clinical presentation in adults. Symptoms of primary genital herpes infection appear after an incubation period of about 3-7 days and include fever, malaise, abdominal pain and groin pain due to lymphadenopathy. Prior to the development of vesicular eruptions, non specific genital symptoms such as pain, pruritus, vaginal discharge and urinary symptoms may be present for 24-48 hours. The herpetic lesions initially appear as erythematous papules which soon become painful vesicles. They may coalesce into larger pustular or ulcerative lesions and persist for up to 14 days. Urinary retention is the presenting symptom in a large proportion of children, particularly the very young. ${ }^{17} 18$ In boys the lesions are commonly limited to the shaft of penis. Concomitant herpetic gingivostomatitis may be present. ${ }^{7}$ In older children nervous system complications are commonly due to HSV1 originating from the oropharynx and rare following genital HSV2 infection. ${ }^{35}$

Recurrent cutaneous HSV lesions in survivors of neonatal $\mathrm{HSV}$ infection occurring in later infancy and early childhood has been recognised since early 1950 s. $^{36}$ Such cuta- 
neous recurrences tended to be progressively less severe both in the number of vesicles and length of time for resolution. ${ }^{37}$ Recurrent HSV encephalitis as a result of periodic activation of latent virus results in progressive neurological and developmental damage. ${ }^{38} 39$ There are no data regarding the rate of recurrences among older children, probably because of the small number of diagnosed cases; however there is no reason to believe it is any different from the pattern found in the adults.

\section{Differential diagnosis}

Early recognition of HSV infection is essential. The rising proportion of SEM cases amongst those with neonatal herpes reported in the USA is due to increased physician awareness and earlier recognition of the characteristic vesicular lesions. ${ }^{840}$ Other conditions causing skin rashes in neonates should be excluded and these include varicella zoster virus infection, enteroviral disease and disseminated CMV disease. Disseminated HSV infection can be difficult to differentiate from bacterial sepsis which can occur concurrently.

In older paediatric age groups, both nonsexually transmitted diseases such as aphthous ulcer, impetigo, erythema multiforme, candidiasis, varicella, as well as sexually transmitted diseases namely primary and secondary syphilis, chancroid, granuloma inguinale and lymphogranuloma venereum, come into the differential diagnosis.

\section{Diagnosis}

Virus isolation remains the gold standard for the diagnosis of HSV infection. In neonates, besides skin vesicles, the virus can be isolated from the oropharynx, conjunctivae, urine, stool and CSF. High risk newborns should have swabs taken at 24 to 36 hours of age from eyes and pharynx for HSV cultures. ${ }^{41}$ In HSV encephalitis, HSV is rarely detectable from these sites although in a small proportion of neonates with accompanying meningitis, CSF may yield the virus in culture or by polymerase chain reaction techniques. Brain biopsy is usually needed for a firm diagnosis. The classic temporal lobe lesion seen in older children and adults with HSV encephalitis is unusual in neonatal HSV encephalitis. Evidence of clinical HSV disease and/or virus isolation from genital tract of the mother may support the diagnosis of neonatal disease.

Tissue culture diagnosis from cytopathic changes may take several days. A rapid diagnosis, so important in neonatal disease, can be made using antigen detection methods on cell culture 24-48 hours after the specimen inoculation; however the sensitivity of this method is poor. Tzanck smears of vesicular lesions prepared at the bedside can demonstrate multinucleated giant cells suggestive of HSV infection in $50 \%$ of cases. ${ }^{42}$

In older children the virus isolation should be followed by HSV typing and, if possible, type specific serological assay in view of possible medicolegal implications. The guidelines prepared by the Working Party of the Royal College of Physicians of London on physical signs of sexual abuse in children, should be strictly adhered to when examining every child with genital herpes infection. ${ }^{43}$

\section{Management}

The family Feelings of guilt are frequently observed in parents of children with neonatal HSV infection. The family of a sexually abused child with HSV infection suffers from feelings of failed responsibility in protection of the child, especially when the abuse is intrafamilial. Surviving children who are handicapped by the long term complications related to the eye and CNS, often place additional stresses on the entire family. Parents may require support from psychologists, marriage counsellors, family physicians and friends. Many neonates with HSV infection are born to mothers who have never had symptomatic HSV infection, who will need counselling with particular emphasis on future pregnancies.

Treatment of the child Neonates exposed to active HSV lesions from first episode HSV infection at delivery, should have viral cultures performed on specimens obtained from their conjunctivae, oropharynx and skin as well as specimens of urine, stool and CSF. Positive culture from any of these specimens in neonates older than 48 hours or abnormal CSF findings, are indications for initiating therapy with specific anti-viral drugs. ${ }^{44}$

All neonatal infections must be treated with intra-venous antiviral drugs. Acyclovir is the drug of choice; vidarabine is equally effective but more toxic. The mortality of all forms of neonatal HSV is reduced with treatment, the highest reduction being in SEM disease and the least in disseminated disease. Severe neurological impairment following SEM disease is also reduced by treatment. ${ }^{45}{ }^{46} \mathrm{As}$ in adults, antiviral treatment has little or no effect on latency. A small number of neonates successfully treated with acyclovir or vidarabine, develop recrudescence of infection shortly after completion of therapy. ${ }^{3847}$ Beyond the neonatal period, the treatment of the condition is similar to that of adults with oral acyclovir therapy, management of urinary symptoms and treatment of superinfections. Particular attention must be paid to the diagnosis of other STD in abused children which may precede or follow an attack of HSV. ${ }^{19}$

Although a thymidine-kinase deficient acyclovir-resistant HSV strain was isolated from an immunocompromised 7 year old child treated with three courses of acyclovir, ${ }^{48}$ antiviral resistance is rare in immunocompetent children. ${ }^{47490}$ Acyclovir suppression may be used in children with very frequent recurrences. The use of topical therapy in recurrences is of questionable value. The value of suppressive therapy in children with visceral recurrences remains uncertain.

Follow up Long term follow up of affected children is essential in order to monitor the possible neurological, developmental and 
ocular complications of neonatal HSV. The cutaneous lesions of recurrent disease are a potential reservoir for HSV transmission to other children and adults. Parental education aimed at the early recognition of lesions in order that hygienic precautions can be encouraged may help to prevent such transmission. In older abused children, recurrences may have adverse psychological sequelae. Recurring systemic symptoms and local pain associated with outbreaks may cause despair and helplessness with secondary effects on education, quality of life and future sexual relationships. Children affected in this way need long term follow up, additional counselling and help from psychologists.

Prevention Careful clinical examination at the onset of labour to detect mothers with herpetic lesions will help prevent a minority of cases of neonatal herpes. Detection of asymptomatic shedders at term is difficult and cannot be predicted from those with asymptomatic shedding during the last trimester. Screening of mothers with a history of genital herpes by sequential HSV cultures in late gestation is not indicated unless cultures are employed to document cessation of virus excretion after clinical recurrence. Caesarean section is indicated for mothers with active first episodes at term. This method of delivery should not, however, be used as a prophylactic measure in women with a history of recurrent genital herpes unless they have active lesions present at the onset of labour. The clinical benefit of obtaining specimens for culture from mothers without lesions to help identify exposed infants has not yet been established. There are current studies which are investigating acyclovir suppression of genital herpes in late pregnancy in mothers with frequent recurrences, but this cannot be generally recommended with the limited published information presently available.

Prevention of transmission in sexually active older paediatric population, in the current absence of an effective, safe vaccine, can be achieved only through adequate counselling and health education.

\section{Cytomegalovirus}

\section{An historical overviez}

Cytomegalovirus was first isolated in the 1950 s, although its causal relationship to devastating neonatal disease had been recognised 40 years earlier. ${ }^{51}$ Since the advent of rubella immunisation, CMV has become the commonest viral cause of intrauterine foetal damage. Post-transfusion CMV syndrome, first described by Kreel in 1960, was reported initially in patients receiving multiple blood transfusions after open heart surgery. ${ }^{52-54}$ The devastating effects of opportunistic CMV disease have since become apparent in posttransplant patients, those on immunosuppressive drugs and, more recently, in AIDS.

Epidemiology

In most Western countries, CMV infection occurs in two age groups; early infancy and early adult life. Stern ${ }^{55}$ reported that in London about $10 \%$ of children had acquired CMV complement fixation (CF) antibodies by the age of one year. In the USA, 36-56\% of infants were found to have CMV viriuria. ${ }^{56}$

Infection of infants may be transmitted during intra-uterine life, during delivery from the infected cervix, and in the post-natal period from ingestion of infected breast milk, from other children in nurseries, day care centres and, probably, from other family members. Transplacental transmission is more likely to occur following primary CMV infection during pregnancy; in the USA, this is reported in about $1 \%$ of deliveries. The risk of developing symptomatic disease in neonates is higher with primary infection during pregnancy than with reactivated infection, especially in the first half of pregnancy. Stern also reported that about $1-2 \%$ of pregnant women in London acquired primary CMV infection and that $50 \%$ of their foetuses were infected at birth

Beyond infancy, little further infection occurs up to the age of $\mathbf{1 5}$ years in most western countries. In countries with crowded living conditions, about $80-90 \%$ of children are infected by the age of 5 years.

The second peak of transmission, particularly in population with high proportion of susceptible sero-negative adolescents, occurs between 15-30 years of age and is related to sexual activity. The absence of any attributable symptoms or signs at the portal of entry of CMV have made it difficult to demonstrate the sexual route of transmission. Carefully analysed epidemiological data, as well as DNA restriction enzyme finger-printing of CMV isolates, have clearly documented the sexual transmission of CMV in both heterosexual and homosexual population in young adults. ${ }^{57-61} \mathrm{CMV}$ is not routinely screened for during investigation of abused children and there are no reports of CMV mononucleosis occurring as a result of such abuse.

\section{Clinical presentation}

The consequences of intra-uterine infection range from asymptomatic infection to rapidly fatal neonatal cytomegalic inclusion disease. CMV inclusion disease presents at birth or shortly afterwards, with jaundice, thrombocytopenic purpura, haemolytic anaemia, hepato-splenomegaly, pneumonitis and often evidence of neurological damage. It is often fatal and surviving neonates frequently have residual brain damage. Minor infections with transient clinical features during the neonatal period may also occur and the residual mild brain damage may not be apparent for months or until school age.

Infections in older children generally go unrecognised. A small proportion of children develop CMV mononucleosis presenting with malaise, fever, pharyngitis, hepatosplenomegaly and, occasionally, rash. This syndrome is also accompanied by transient atypical lymphocytosis and hepatitis. Although mental retardation as a result of 
CMV infection in this age group has not been reported, chronic CMV infection has been suggested as a cause of non-febrile seizure in children. ${ }^{62}$

\section{CMV in immunosuppression}

Latent virus, probably maintained within leucocytes, may be reactivated in immunosuppressed individuals causing recurrent symptomatic CMV infection. ${ }^{63}$ In the 3-4 months after transplantation, mononucleosis, unexplained leucopenia, pneumonia and/or hepatitis often occur as a result of CMV reactivation. At a later stage retinitis and, less commonly, encephalitis can develop. In HIV infected children, Frenkel ${ }^{64}$ reported active CMV infection in about $45 \%$ of those with symptomatic disease. CMV retinitis is the most frequent cause of sight threatening disease in the corresponding adult population, however the incidence of blindness in paediatric AIDS is reportedly low. ${ }^{65}$

\section{Diagnosis}

Isolation of CMV from urine, saliva, semen and cervical secretion is insufficient to ascribe a causative role for $\mathrm{CMV}$ to the clinical features under investigation. Detection of CMV in the urine of a newborn within the first week of life establishes congenital infection, but does not distinguish symptomatic from asymptomatic infants. Isolation of the virus from buffy coat leucocytes, however, has been found to have a high correlation with the presence of CMV disease. ${ }^{66}$ Active infection is strongly suggested by seroconversion and the demonstration of CMV specific IgM antibody. The presence of typical cytomegalic inclusion cells in biopsy specimens is also indicative of an ongoing tissue infection. Prenatal diagnosis of CMV infection can be made on amniotic fluid culture; however, the sensitivity of this diagnostic method is unknown. ${ }^{67}$

\section{Treatment}

Treatments for CMV infection in children of unproven value have previously included floxuridine, idoxuridine and cytarabine. ${ }^{68}$ Vidarabine and acyclovir have also been used, but without satisfactory effect. Ganciclovir and foscarnet are currently the two drugs in use for treatment of both AIDS-related and AIDS-unrelated CMV disease. Recurrence of CMV disease in immunosuppressed individuals is common and maintenance therapy with these drugs is essential. Children with a high risk of developing CMV disease, such as after transplantation, are usually given prophylactic therapy. Acyclovir has been reported to be useful for prevention of CMV disease in bone marrow allograft recipients in whom ganciclovir and foscarnet carry a high mortality. In renal transplant patients, acyclovir prophylaxis is also reported to be effective. Concomitant administration of immune globulin may additionally limit serious CMV disease in these situations. ${ }^{69}$

\section{Prevention}

Prevention of neonatal CMV disease will be directly related to prevention of primary CMV disease during pregnancy. In the West, the number of girls reaching child bearing age with CMV seronegative status has steadily increased, making them vulnerable to primary disease at pregnancy. Two attenuated live virus vaccines are being tested for use in women of child bearing age. ${ }^{70}$ Among healthy seronegative volunteers, over $95 \%$ had shown seroconversion with these vaccines and infants born to immunised mothers had no detectable CMV infection. Further studies are needed regarding the safety and effectiveness of these vaccines.

\section{Hepatitis b}

\section{An historical overview}

During the early twentieth century, jaundice was frequently encountered as a complication of intravenous arsenical injections for syphilis. ${ }^{7172}$ During this same period, plasma administration for immunoprophylaxis in measles and mumps, as well as administration of vaccines containing human serum, such as for yellow fever, and blood transfusions were al.o noted to be complicated by the development of jaundice. ${ }^{7374}$ After observing that intravenous drugs were given using inadequately sterilised syringes and needles between patients, Bigger ${ }^{71}$ suggested that the jaundice might be due to transmission of a virus from patient to patient. Most of these cases were undoubtedly due to Hepatitis B virus (HBV). It was the discovery of Australia antigen by Blumberg in $1965^{75}$ and its eventual association with serum hepatitis that made positive diagnosis of this condition possible.

\section{Epidemiology}

HBV infection occurs throughout the world with widely varying prevalence rates. It is endemic in most developing countries where about $95 \%$ of the 300 million worldwide chronic HBV carriers live. ${ }^{76}$ The prime reason for the persistence of high rates of chronic $\mathrm{HBV}$ infection in these populations, is the acquisition of infection during early childhood. ${ }^{77}$ The risk of persistent HBV infection in children is inversely related to the age of initial infection; the reported risk is $70-90 \%$, $60 \%$ and $10 \%$ when the infection is transmitted perinatally, during the second year of life, and at 6 years of age, respectively. ${ }^{78-80}$

Intra-uterine transmission is the route of infection in only $5 \%-10 \%$ of neonatal HBV infections. ${ }^{81}$ The vast majority of neonatal HBV infections are a consequence of transmission at delivery or during the early postpartum period. The rate of transmission from mother to infant depends upon maternal infectivity; it is approximately $85 \%$ if she is e antigen ( $\mathrm{HBeAg}$ ) positive and $31 \%$ if $\mathrm{HBeAg}$ negative. ${ }^{82}$ In South-east Asia, perinatal infection is more common because of the larger proportion of $\mathrm{HBeAg}$ positive parturient women, as compared with Africa, Middle East and Arctic where fewer than $20 \%$ of $\mathrm{HBsAg}$ positive mothers are also $\mathrm{HBeAg}$ positive $^{83-85}$ In high and intermediate endemic 
areas, substantial transmission also occurs during the early childhood period from infected family members, at schools and in institutions. ${ }^{82}$ 86-88 Beasley $^{83}$ reported that in Taiwan, $10.6 \%$ of preschool children seroconverted during a 2 year follow up. A significant correlation between the frequency of injections, particularly those administered in rural hospitals, and the incidence of HBV infections in children has also been reported, indicating that contaminated needles is another source of infection. Similarly, ear piercing and scarification in children had been related to $\mathrm{HBV}$ transmission in parts of Africa. ${ }^{86}$

In most developed countries, the prevalence of chronic $\mathrm{HBV}$ is less than $2 \%$ and transmission occurs primarily among adults. Only $1-3 \%$ of all $\mathrm{HBV}$ infection in these countries occur in children under 5 years of age; however, they account for $20-30 \%$ of all chronic infections. ${ }^{77}$ In the USA, sexual transmission of $\mathrm{HBV}$ is the route of infection in $50 \%$ of teenage children who present with acute HBV infection. Reviewing the STD in rape victims, Glaser in $1989^{89}$ could find no reported cases of $\mathrm{CMV}$ or $\mathrm{HBV}$ infection in children known to have been sexually abused. However, the risk is likely to be significant in high endemic areas.

\section{Clinical presentation}

In over $90 \%$ of neonates and young children, $\mathrm{HBV}$ infection is asymptomatic. Beasley ${ }^{83}$ found no cases of clinical hepatitis among the 1,110 Chinese children studied in Taiwan. Neonates and young children often remain HBsAg positive for life. Studies in Japan, Taiwan and other endemic areas had shown that most children, in spite of showing persistent antigenemia, thrive and show no clinical evidence of hepatic disease. Schweitzer ${ }^{9091}$ reported that many children, however, show variable elevated levels of transaminases and histological evidence of persistent mild hepatitis. The mild persistent hepatitis is not always clinically stable, as some children followed up for a long term, will develop chronic liver disease. ${ }^{9293}$ Neonatal HBV infection with persistent antigenemia can also progress to cirrhosis and hepato-cellular carcinoma.

Those neonates who develop overt hepatitis generally do so as the passive immunity wanes 2-3 months after birth. The severity of infection ranges from mild hepatitis with rapid recovery to fulminant hepatitis. Fulminant hepatitis B is rare, but carries a high mortality and high risk of cirrhosis development in survivors. ${ }^{94-95}$

\section{Diagnosis}

Sero-diagnosis in HBV infection is reliable, sensitive and specific. Detection of $\mathrm{HBsAg}$, a positive anti-HBc IgM fraction and a rising anti-HBc titre are indicative of acute infection. In some patients, $\mathrm{HBsAg}$ is undetectable at clinical presentation. Presence of anti-HBs and anti-HBc antibodies without $\mathrm{HBsAg}$ or anti-HBc IgM, is consistent with past infection. Persistence of HBsAg and a high titre of
anti-HBc is indicative of chronic infection.

\section{Treatment}

In chronic hepatitis B infection, treatment with interferon-alpha has been reported to result in seroconversion from $\mathrm{HBeAg}$ to Anti$\mathrm{HBe}$ status with loss of serum HBV DNA, in $30-50 \%$ of patients. ${ }^{96}$ The effect of this therapy on the occurrence of cirrhosis and malignancy is not known. Many other therapeutic agents, both antiviral and immunomodulators, have shown disappointing results; other trial drugs are being assessed for their effectiveness in chronic Hepatitis B infection.

\section{Prevention}

Prevention of transmission, identification of at-risk populations, and protection through effective vaccination should be the basis for effective control of this infection.

Most infants born to $\mathrm{HBV}$ infected mothers are HBV negative at birth, but become positive within the first three months of life. Immunoprophylaxis, therefore, should be effective in preventing neonatal infection and hence reduce the size of $\mathrm{HBV}$ carrier population. Stevens ${ }^{97}$ demonstrated that use of both Hepatitis B immunoglobulin and Hepatitis B vaccine at birth in "at risk" children reduced the carrier rate from $85 \%$ to $14 \cdot 2 \%$. Both the plasma-derived and recombinant DNA vaccines are safe and have been demonstrated to be effective in over $95 \%$ of immunocompetent people. ${ }^{98}$ Current recommendations for the prevention of neonatal HBV infection are to give both active and passive immunisation at birth. Countries with high endemic HBV infection are developing strategies for the effective use of hepatitis B vaccine. In low endemic countries, such as the UK, the vaccination programmes are generally limited to identified, mainly adult, risk populations.

\section{Molluscum contagiosum}

\section{An historical overview}

There have been descriptions of molluscum contagiosum (MC) in the medical literature since $1817.9^{9}$ The transmissible nature of material from lesions, earlier called Henderson-Patterson bodies, has been known since the early 19th century; however, the MCs have also been described as epitheliomas and parasitic nodules. In 1905, Juliusburg established their viral nature by transmitting the disease using a filtrate of MC fluid. Recently, restriction endonuclease analysis of molluscum contagiosum virus (MCV) DNA has revealed the existence of two viral subtypes namely MCV1 and MCV11.

\section{Epidemiology}

MC is prevalent worldwide and affects two different age groups; children and young adults. Childhood MC is particularly common in Papua New Guinea, Fiji and certain parts of Africa. ${ }^{100} 101$ In these countries the disease is most commonly seen in 
children aged less than 5 years and, in some geographical regions, a prevalence rate approaching $25 \%$ has been reported. Adolescent MC is commonly seen in STD clinic attenders.

The infection is commonly acquired through close skin to skin contact; fomites, swimming pools, public baths, towels, gymnasium equipment and benches have been implicated. ${ }^{99}$ Skin contact associated with sexual intercourse is the mode of transmission in young adults. The MCV type 1 is much more prevalent than MCV type 11 but neither subtype is exclusively associated with genital or non-genital lesions. ${ }^{102-104}$ However, MCV type 11 is rare in children below 15 years of age.

Clinical features

MC is a localised proliferative skin lesion which is confined to the epidermis. The lesions are smooth, firm, raised and flesh coloured nodules measuring about $2-5 \mathrm{~mm}$ in diameter which often show a typical central depression. In children, the lesions are more often found in the face, trunk and limbs whereas in young adults they are commonly found around the genital area. They can also occur on the eye-lids and may infect the conjunctiva, but they are rare on the palms and soles. The number of lesions can vary greatly and lesions in their hundreds have been described in children from endemic areas. In atopic dermatitis and immunosuppressed conditions including AIDS, multiple, widespread, persistent and disfiguring lesions can occur especially in the face. ${ }^{105-107}$ The MCs can coalesce to form plaques of confluent lesions. ${ }^{108109}$ Development of profuse lesions of MCs may be the presenting feature of other underlying systemic diseases associated with immune suppression. ${ }^{110}$

Most patients with MC lesions are asymptomatic. A few patients may have pruritus and tenderness. "Molluscum dermatitis", an eczematous area around MC lesions has been described in about $10 \%$ of patients. ${ }^{111112}$ Individual lesions may become inflamed and resemble furuncles.

\section{Diagnosis}

MC is usually diagnosed clinically, based on the classic appearance of the lesions; additional diagnostic procedures are seldom needed. Atypical MC lesions or typical MC lesions in unusual anatomic sites can be shown histologically or cytologically to contain molluscum bodies. Other laboratory methods used to confirm the diagnosis include electron microscopy of fixed material from a lesion and MC specific antigen detection by fluorescent antibody technique. In AIDS, cutaneous cryptococcal lesions, when presenting in large numbers, can resemble MC and histologic examination will be necessary for a definitive diagnosis. ${ }^{113} 114$

\section{Treatment}

In immunocompetent individuals, MC lesions often resolve spontaneously if left untreated; each lesion may persist for about two months. ${ }^{115}$ The lesions, however, especially in immunosuppressed states, may continue to erupt and persist in spite of treatment. The prognosis is generally determined by the underlying condition. In children with hundreds of lesions and who are otherwise well, the treatment may have to be carried out under general anaesthesia for cosmetic reasons as well as to prevent autoinoculation, superinfection and transmission. ${ }^{116}$

Treatment of MCs involves mechanical removal of virus containing material. This is usually carried out by breaking the MC lesion and cauterising the open skin using either chemical irritants, such as phenol, or electrocauterisation. Cryotherapy with liquid nitrogen is also effective. There are no reports of any effective systemic therapy for this condition.

\section{Future developments}

Success in the control of viral STDs in general will depend on the prevention of transmission of infection, reduction of "carrier population" and improved awareness among the public and health profession. Just as the development of vaccination now permits prevention programmes against hepatitis B in neonates, there is a clear need to develop effective vaccines against the herpes viruses, especially HSV and CMV. An effective vaccine against $H S V$ is still a distant prospect and health education of the general public is likely to have only limited impact. Improved methods for rapid diagnosis of neonatal herpes and new antiviral drugs which combine the wide therapeutic index of acyclovir with increased efficacy and less frequent dosing intervals are needed. The wider availability of serological assays for type specific antibodies to HSV is essential to promote better understanding of local prevalence and help identify mothers who may be at increased risk of acquiring $\mathrm{HSV}$ during pregnancy.

In CMV infection, prospects for an effective vaccine are possibly nearer, but there is an urgent need for more effective, less toxic drugs for treatment of active disease. Oral preparations of ganciclovir currently on trials in adults would be an advance but is unlikely to answer all the problems of management of immunocompromised children.

1 Hutfield DC. History of herpes genitalis. $\mathrm{Br} \mathcal{F}$ Venereal Dis 1966;42:263-8.

2 Nahmias AJ, Dowdle WR. Antigenic and biologic differences in Herpes virus hominis. Prog Med Virol 1968; 10:110-59.

3 Lee FK, Coleman RM, Periera L, et al. Detection of Herpes simplex virus type 11-specific antibody with glycoprotein G. f Clin Microbiol 1985;22:641-4.

4 Nahmias AJ, Lee FK, Beckman-Nahmias S Seroepidemiological and sociological patterns of Herpes simplex virus infection in the world. Scand $\mathcal{f}$ Infect Dis simplex virus infection

5 Ho DWT, Field PR, Sjogren-Jansson E, et al. Indirect ELISA for the detection of HSV-2 specific IgG and IgM antibodies with glycoprotein G (gG-2). 7 Virol Methods 1992;36:249-64.

6 Hass GM. Hepato-adrenal necrosis with intranuclear inclusion bodies. Am $\mathcal{F}$ Pathol 1935;X1:127-42.

7 Nahmias AJ, Dowdle WR, Naib ZM, et al. Genital infection with Herpes virus hominis types 1 and 2 in children. Pediatrics 1968;42:659-66. 
8 Arvin AM, Prober CG. Herpes simplex virus infections. Pediatric Infect Dis F 1990;9:765-7.

9 Ades AE, Peckham CS, Dale GE, et al. Prevalence of antibodies to herpes simplex virus types 1 and 2 in pregnant women and estimated rates of infection. F Epidiol Community Health 1989;43:53-60

10 Templeton AC. Generalised Herpes simplex in malnourished children. F Clin Pathol 1970;23:24-30.

11 Nahmias AJ, Josey WE, Naib ZM, et al. Perinatal risks associated with maternal genital Herpes simplex virus infection. Am 7 Obstet Gynecol 1971;110:825-33.

12 Whitley RJ, Nahmias AJ, Visintine AM, et al. The natural history of Herpes simplex virus infection of mother and newborn. Pediatric 1980;66:489-94.

13 Yeager AS, Arvin AM. Reasons for the absence of a history of recurrent genital infections in mothers and neonates infected with Herpes simplex virus. Pediatrics 1984;73:188-93

14 Sullivan-Bolyai J, Hull HF, Wilson C, et al. Neonatal Herpes simplex virus infection in King Country, Washington: Increasing incidence and epidemiologic correlates. $\mathcal{F} A M A$ 1983;250:3059-62.

15 Krugman S. Primary herpetic vulvovaginitis: a report of a case; isolation and identific

16 Scott TFM, Coriell L, Blank H, et al. Some comments on herpetic infection in children with special emphasis on herpetic infection in children with special emphasis on unusual c

17 Lazar MP. Primary herpetic vulvovaginitis. Arch Dermatol 1955;72:272-4.

18 Hare MJ, Mowla A. Genital herpes virus infection in a prepubertal girl. Br $\mathcal{F}$ Obstet Gynaecol 1977;84:141-2.

19 Gardner M, Jones J. Genital herpes acquired by sexual abuse of children. $\dot{\mathcal{F}}$ Pediatr 1984;104:243-4.

20 Kaplan KM, Fleisher GR, Paradise JE, et al. Social relevance of genital Herpes simplex in children. $A m \mathcal{F} D$ is Child 1984;138:872-4.

21 Jenny C. Sexually transmitted diseases and child abuse. Pediatric Ann 1992;21:497-503.

22 Lindsay D, Embree J. Sexually transmitted diseases: a significant complication of childhood sexual abuse. Can $\mathcal{F}$ Infect Dis 1992;3:122-8.

23 Gardner JJ. Comparison of vaginal flora in sexually abused and non-abused girls. F Pediatr 1992;120: 872-7.

$24 \mathrm{Ng} \mathrm{AB}$, Reagan JW, Yen SS. Herpes genitalis: clinical and cytopathic experience with 256 patients. Obstet Gynecol 1970;36:645-51.

25 Goodsell SE, Quinn TC, Mkrtichian E, et al. Herpes simplex virus proctitis in homosexual men: clinical, sigmoidoscopic and histopathological features. $N$ Engl $f$ Med 1983;308:868-71.

26 DeJong AR, Emmett GA, Hervada AA. Epidemiologic factors in sexual abuse of boys. Am $\mathcal{f}$ Dis Child 1982;136:990-3.

27 Stagno S, Whitley RJ. Herpes simplex virus infection in the neonates and children. In: Holmes KK, Mardh PA, Sparling PF, Wiesnet PJ, eds, Sexually transmitted diseases. New York, McGraw Hill 1990.

28 Arvin AM. Relationships between maternal immunity to herpes simplex virus and the risk of neonatal Herpes virus infection. Rev Inf Dis 1991;13 (suppl.):S953S956.

29 Sullender WM, Yasukawa LL, Schwartz M, et al. Type specific antibodies to herpes simplex virus type-2 (HSV2) glycoprotein $G$ in pregnant women, infants exposed to maternal HSV-2 infection at delivery and infants with neonatal herpes. $\mathcal{F}$ Infect $D$ is $1988 ; 157: 164-71$.

30 Ashley RL, Delessio J, Burchett S, et al. Herpes simplex virus type-2 (HSV-2) type specific antibody correlates of virus type-2 (HSV-2) type specific antibody correlates of protection in infants

31 Brown ZA, Benedetti J, Ashley RL, et al. Neonatal herpes simplex virus infection in relation to asymptomatic maternal infection at the time of labour. $N$ Eng $\mathcal{F} \mathrm{Med}$ 1991;324:1247-52.

32 Sullender WM, Miller JL, Yasukawa LL, et al. Humoral and cell-mediated immunity in neonates with herpes simplex virus infection. $\mathcal{F}$ Infect Dis 1987;155:28-37.

33 Kohl S, West MS, Prober CG, et al. Neonatal antibodydependent cellular cytotoxic antibody levels are associated with the clinical presentation of neonatal herpes simplex virus infection. $\mathcal{F}$ Infect Dis 1989;160:770-6.

34 Koskiniemi M, Happonen JM, Jarvenpaa AL, et al. Neonatal Herpes simplex virus infection: a report of 43 Neonatal Herpes simplex virus infection:

35 Shturman-Ellstein R, Borkowski W, Fish I, et al. Myelitis associated with genital herpes in a child. $\mathcal{f}$ Pediatr 1976;88:523.

36 Florman AL, Mindlin BL. Generalised herpes simplex in an eleven day old premature infant. Am $\mathcal{F}$ Dis Child 1952;83:481-6.

37 Hovig DE, Hodgman JE, Mathies AW, et al. Herpes virus hominis (simplex) infection in the newborn with recurrences during infancy. $\mathrm{Am} F \mathrm{Dis}$ Child 1968; 115:438-44.

38 Gutman LT, Wilfort CM, Eppes S. Herpes simplex virus encephalitis in children: analysis of cerebrospinal fluid and progressive neuro-developmental deterioration. and progressive nis 1986;154:415-21.

39 Reuman PD, Cooper DL, Ayoub EM. Diffuse recurrent Herpes simplex virus skin lesions after adequate therapy Herpes simplex virus skin lesions after adequate
with vidarabine. Pediatr Infect Dis 1986;5:97-9.
40 Whitley RJ, Corey 1, Arvin A, et al. Changing presentation of herpes simplex virus infection in neonates. $\mathcal{f}$ Infect dis. 1988;158:109-16.

41 Feder HM. Disseminated Herpes simplex infection in a neonate during prophylaxis with Vidarabine. $\mathfrak{F} A M A$ 1988;259:1054-5

42 Corey L, Holmes KK. Genital Herpes simplex virus infections: current concepts in diagnosis, therapy and prevention. Ann Intern Med 1983;98:973-83.

43 Priestley B, Hull D. Interpreting the signs of sexual abuse of children. $R$ Coll Physicians Lond 1991;25:84-6.

44 Prober CG, Corey L, Brown ZA, et al. The management of pregnancies complicated by genital infections with herpes simplex virus. Clin Inf Dis 1992;15:1031-8.

45 Whitley RJ, Nahmias AJ, Soong S-J, et al. Vidarabine therapy of neonatal herpes simplex virus infection. Pediatrics 1980;66:495-501.

46 Whitley RJ, Yeager A, Kartus P, et al. Neonatal herpes simplex virus infection: follow-up evaluation of vidarabine therapy. Pediatrics 1983;72:778-85.

47 Rabalis GP, Nusinoff-Lerhman S, Arvin AM, et al. Antiviral susceptibilities of herpes simplex virus isolates from infants with recurrent muco-cutaneous lesions after neonatal infection. Pediatr Infect Dis $\mathcal{f} 1989$ 8:221-3.

48 Crumpacker CS, Schnipper LE, Marlowe SJ, et al. Resistance to antiviral drugs of herpes simplex virus isolated from a patient treated with acyclovir. $N$ Eng $\mathcal{f}$ Med 1982;306:343-6.

49 McLaren C, Corey L, Dekket C, et al. In vitro sensitivity to acyclovir in genital herpes simplex viruses from acyclovir treated patients. F Infect Dis 1983;148:868-75.

50 Struass SE, Takiff HE, Seidlin M, et al. Suppression of frequently recurring genital herpes. A placebo controlled double blind trial of oral acyclovir. $N$ Eng $\mathcal{f} \mathrm{Med}$ 1984;310:1545-50.

51 Lang DJ. Cytomegalovirus infections in pregnancy and the newborn. Clin Obstet Gynecol 1970;13:348-59.

52 Kreel I, Zaroff LI, Canter JW, et al. A syndrome following total body perfusion. Surg Gynecol Obstet 1960;111: 317-21.

53 Smith DR. A syndrome resembling infectious mononucleosis after open heart surgery. BMF 1964;1:945-8.

54 Lang DJ, Scolnick EM, Willerson JT. Association of cytomegalovirus infection with the postperfusion syndrome. N Engl F Med 1968;278:1147-9.

55 Stern H. Cytomegalovirus infection. Br f Clin Pract 1975;29:245-50.

56 Ho M. Epidemiology of cytomegalovirus infection. Rev Inf Dis 1990;12 (suppl):s701-s710.

57 Davies LE, Stewart JA, Garvin S. Cytomegalovirus infection: A seroepidemiologic comparison of nuns and women from a venereal disease clinic. Am $\mathcal{f}$ Epidemiol 1975;102:327-30

58 Handsfield $\mathrm{HH}$, Chandler SH, Caine VA, et al. Cytomegalovius in sex partners; evidence for sexual Cytomegalovius in sex partners; eviden
transmission. F Infect Dis 1985;151:344-8.

59 Chandler SH, Holmes KK, Wentworth BB, et al. The epidemiology of cytomegaloviral infection in women attending a sexually transmitted disease clinic. $\mathcal{F}$ Infect Dis 1985;152:597-605.

60 Collier AC, Meyers JD, Corey L, et al. Cytomegaloviru infection in homosexual men. Relationship to sexual practices, antibody to human immunodeficiency virus and cell mediated immunity. $A m$ f Med 1987;82 593-601.

61 Collier AC, Hansfield H, Roberts PL, et al. Cytomegalovirus infection in women attending a sexually transmitted disease clinic. $f$ Inf Dis 1990; 162:46-51.

62 Iannetti P, Fiorilli M, Sirianni MC, et al. Non-febrile seizures after febrile convulsions: possible role of chronic cytomegalovirus infection. $\mathcal{F}$ Pediatr 1982;101 27-31.

63 Adler SP. Transfusion-associated cytomegalovirus infections. Rev Inf Dis 1983;5:977-93.

64 Frenkel LD, Gaur G, Tsolia M, et al. Cytomegalovirus in children with AIDS. Rev Inf Dis 1990;12 (suppl) s820-s826.

65 Butler KM, Pizzo PA. Pediatric human immunodeficiency virus infection. In: Gorback SL, Bartlett JG, Blacklow NR eds. Infectious diseases. Philadelphia. WB Saunders 1992.

66 van der Bij W, Torensma $R$, va Son WJ, et al. Rapid immunodiagnosis of active cytomegalovirus infection by monoclonal antibody staining of blood leucocytes. Med Virol 1988;25:179-88.

67 Grose C, Weiner CP. Prenatal diagnosis of congenital cytomegalovirus infection: two decades later. $\mathrm{Am} \mathscr{f}$ Obstet Gynecol 1990;163:447-50.

68 Balfour HH. Management of cytomegalovirus disease with antiviral drugs. Rev Inf Dis 1990;12 (suppl) s849-s860.

69 Merigan TC, Resta S. Cytomegalovirus: where have we been and where are we going? Rev Inf Dis 1990;12 (suppl):s693-s700.

70 Porath A, McNutt RA, Smiley LM, et al. Effectiveness and cost benefit of a proposed live cytomegalovirus vaccine in the prevention of congenital disease. Rev Inf Dis. 1990;12:31-40.

71 Bigger JW, Dubl SCD. Jaundice in syphilitics under treatment. Lancet 1943;i:457-8.

ment. Lancet 1943;i:457-8.
72 MacCallum FD. Transmission of arsenotherapy jaundice by blood: failure with faeces and nasopharyngeal wash- 
ings. Lancet 1945;i:342.

73 Beeson PB, Chesney G, McFarlan AM. Hepatitis following injection of mumps convalescent plasma. Lancet 1944;i:814-5.

74 Robinson WS. Hepatitis $B$ virus and the delta agent. In: Mandell GL, Douglas RG, Bennet JE, eds. Principles and practice of infectious diseases. New York: Wiley Medicals, 1985.

75 Blumberg BS, Harvey JA, Visnich S. A "new" antigen in leukaemia sera. $\mathcal{F} A M A 1965 ; 191: 541-6$.

76 Ayoola EA. Viral hepatitis in Africa. In: Zuckerman AJ ed. Viral hepatitis and Liver Disease. New York: Alan R Liss Inc, 1988.

77 Margolis HS, Alter MJ, Hadler SC. Hepatitis B: evolving epidemiology and implications for control. Seminars in epidemiology and implication

78 Stevens CE, Neurath RA, Beasley RP, et al. HBeAg and anti-HBs detection by radioimmunoassay. Correlation with vertical transmission of hepatitis $B$ virus in Taiwan. f Med Virol 1979;3:237-41.

79 Beasley RP, Hwang L-Y: Postnatal infectivity of Hepatitis B surface antigen-carrier mothers. F Infect Dis 1983, 147:185-90.

80 McMahon BJ, Alward WLM, Hall DM, et al. Acute Hepatitis B virus infection: relation of age to the clinical expression of disease and subsequent development of the carrier state. $\mathcal{F}$ Infect $D$ is 1985;151:599-603.

81 Koff RS. Hepatitis B and Hepatitis D. In: Gorbach SL, Bartlett JG, Blacklow NR eds. Infectious Disease. Bartlett JG, Blacklow NR eds.

82 Beasley RP, Trepo C, Stevens CE, et al. The e antigen and vertical transmission of Hepatitis B surface antigen. Am $\mathcal{F}$ Epidemiol 1977;105:94-8.

83 Beasley RP, Hwang L-Y, Lin C-C, et al. Incidence of Hepatitis $B$ virus infection in preschool children in Taiwan. F Infect Dis 1982;146:198-204.

84 Marinier E, Barrois V, Laronze B, et al. Lack of perinatal transmission of Hepatitis B virus infection in Senegal, West Africa. F Paediatr 1985;106:843-9.

85 Hyams KC, Osman NM, Khaled EM, et al. Maternalinfant transmission of Hepatitis B in Egypt. $\mathcal{F}$ Med Virol 1988;24:191-7.

86 Karim SSA, Coovadia HM, Windsor IM, et al. The prevalence and transmission of Hepatitis B virus infection in urban, rural and institutionalised black children of urban, rural and institutionalised black children of Natal/KwaZulu,

87 Taylor R, Montaville B, Levy S, et al. Hepatitis B infection in Vanuatu: age of acquisition of infection and possible routes of transmission. Asia-Pacific $\mathcal{F}$ Pub Health 1989;3:205-12.

88 Norkrans G. Epidemiology of Hepatitis B virus (HBV) infections with particular regard to current routes of transmission and development of cirrhosis and malig nancy. Scand $\mathcal{F} \operatorname{Inf} D$ is 1990;69:43-7.

89 Glaser JB, Hammerschlag MR, McCormack WM. Epidemiology of sexually transmitted diseases in rape victims. Rev Inf $D$ is 1989;11:246-54.

90 Schweitzer Il, Dunn AE, Peters RL, et al. Viral Hepatitis $\mathrm{B}$ in neonates and infants. Am $\mathcal{J}$ Med 1973;55: 762-71.

91 Schweitzer II. Vertical transmission of the Hepatitis B surface antigen. $\mathrm{Am}$ f Med Sci 1975;270:287-91.

92 Tong $M$, Thursby M, Rakela J, et al. Studies on the maternal-infant transmission of the viruses which cause acute Hepatitis. Gastroenterology 1981;80:999-1004.

93 Crumpacker CS. Hepatitis. In: Remington JS and Jerome $\mathrm{OK}$ eds. Infectious Diseases of the Foetus and Newborn
Infant 2nd Ed. Philadelphia: WB Saunders, 1983.

94 Kattamis CA, Demetrios D, Matsaniotis NS. Australia antigen and neonatal hepatitis syndrome. Pediatrics 1974;54:157-64

95 Dupuy JM, Frommel D, Alagille D. Severe viral hepatitis type B in infancy. Lancet 1975;ii:191-4.

96 Davis GL. Treatment of chronic hepatitis B. Hepatology 1991;14:567-9.

97 Stenvens CE, Toy PT, Tong MJ, et al. Perinatal Hepatitis B virus transmission in the United States: prevention by passive-active immunization. $\mathcal{F A M A} 1985 ; 253: 1740-5$.

98 Centers for disease control: update on hepatitis B prevention. Recommendations of the immunization practices tion. Recommendations of the immunization practices
advisory committee. Ann Intern Med 1987;107: advisory

99 Brown ST, Nalley JF, Kraus SJ. Molluscum contagiosum. Sex Tran Dis 1981;8:227-34.

100 Postlesthwaite R, Watt JA, Hawley TG, et al. Features of molluscum contagiosum in the North-East of Scotland and in Fijian village settlements. Fournal of Hygiene, Cambridge 1967;65:281-91.

101 Stuart RJ, Muller HK, Francis GD. Molluscum contagiosum in villages of the West Sepik district of New Guinea. Med $\mathcal{F}$ Austr 1971;2:751-4.

102 Porter CD, Muhlemann MF, Cream JJ, et al. Molluscum contagiosum: characterization of viral DNA and clinical features. Epidemiol Infect 1987;99:563-7.

103 Scholz J, Rosen-Wolff A, Bugert J, et al. Molecular epidemiology of molluscum contagiosum. $\mathcal{F}$ Infect Dis demiology of mollus

104 Porter CD, Blake NW, Archard LC, et al. Molluscum contagiosum virus types in genital and non-genital lesions. Br F Dermatol 1989;120:37-41.

105 Rosenberg EW, Yusk JW, Memphis Molluscum contagiosum: eruption following treatment with prednisone and methotrexate. Arch Dermatol 1970;101:439-41.

106 Pauly CR, Artis WM, Jones HE. Atopic dermatitis, impaired cellular immunity and molluscum contagiosum. Arch Dermatol 1978;114:391-3.

107 Lombardo PC. Molluscum contagiosum and the acquired immunodeficiency syndrome. Arch Dermatol 1985;121:834-5.

108 Lynch PJ, Minkin W, Benning F. Molluscum contagiosum of the adult. Arch Dermatol 1968;98:141-3.

109 Peachy RDG. Severe molluscum contagiosum infection with $\mathrm{T}$ cell deficiency. $\mathrm{Br} \quad \mathcal{f}$ Dermatol $1977 ; 97$ (suppl):49-50.

110 Ganpule M, Garretts M. Molluscum contagiosum and sarcoidosis. Br f Dermatol 1971;85:587-9.

111 DeOreo GA, Johnson HH, Birkley GW. An eczematous reaction associated with molluscum contagiosum. Arch Dermatol 1956;74:344-8.

112 Kipping HF. Molluscum dermatitis. Arch Dermatol 1971;103:106.

113 Picon L, Vaillant L, Duong T, et al. Cutaneous cryptococcosis resembling molluscum contagiosum: a first manifestation of AIDS. Acta Dermato-venereologica 1989;69:365-7.

114 Ghigliotti G, Carrega G, Farris A, et al. Cutaneous cryptococcosis resembling molluscum contagiosum in a homosexual man with AIDS. Report of a case and review of the literature. Acta Dermato-venereologica 1992; review of

115 Hawley TG. The natural history of molluscum contagiosum in Fijian children. Fournal of Hygiene, Cambridge 1970;68:631-632.

116 Kaye JW, Belleville NJ. Problems in therapy of molluscum contagiosum. Arch. Dermatol 1966;94:454-5. 